\title{
4
}

\section{Epilepsy: Selenium and Aging}

\author{
Caroline Rocourt, Ying Yu and Wen-Hsing Cheng \\ Department of Nutrition and Food Science, University of Maryland, College Park
}

USA

\section{Introduction}

Epilepsy affects nearly 50 million people worldwide and is a disease that involves spontaneous frequent seizures caused by electrical disturbances in the brain (Bergen 1998; Meinardi, Scott et al. 2001). Epilepsy is a syndrome, or a collection of symptoms, in which people are predisposed to seizures (Fisher, van Emde Boas et al. 2005; Gomez-Alonso and Giraldez 2007; Jaseja 2009). Epilepsy diagnosis usually occurs after permanent injury to the brain or from inborn errors that cause brain tissue to become abnormally excited (Fisher, van Emde Boas et al. 2005). Health statistics show that children less than 2 and adults older than 65 are the most likely populations to develop epilepsy and that seizure events increase the risk of mortality in the individual (Feng 1978; Tsai 2005; Fountain, Van Ness et al. 2011). It is thought that nearly $4 \%$ of the US population will have seizure activity in their lifetimes, with many having seizures and never being aware they occurred.

In some types of epilepsy, the cause of the seizures cannot be clearly defined and does not present with other neurological disorders (Lerman, Sagie et al. 2011). Certain types of epilepsy have a genetic component (Poduri and Lowenstein 2011; Sisodiya and Mefford 2011; Sozmen, Baybas et al. 2011; Wilke, Worrell et al. 2011), but the most common diagnoses of epilepsy occur after neurological damage such as a stroke, transient ischemic attacks, a diagnosis of dementia, traumatic brain injury, brain abscesses, meningitis, encephalitis, neurosyphilis, brain tumors, hematomas, abnormal blood vessels, AIDS, congenital brain defects, metabolic diseases such as phenylketonuria, and liver or kidney failure.

Epileptic seizures range in severity from staring spells to violent convulsions and loss of consciousness (Haut, Lipton et al. 2005; Maillard, Vignal et al. 2009). Given the wide variety of factors that can precipitate epilepsy, it stands to reason that type of seizure is dependent on the location and type of the brain injury. Upon physical examination, many people suffering from epilepsy appear healthy (Maganti, Gerber et al. 2008). Most epileptics will present with clinical abnormal electrical activity as measured by an electroencephalograph (Urbach 2005). Epilepsy is further classified as idiopathic (presumed genetic basis), symptomatic (due to a structural abnormality) or cryptogenic (cause is undetermined) (Kwan and Brodie 2000; Berg and Kelly 2006; Farrell, Wirrell et al. 2006).

Unfortunately, after some epileptic events, there is a risk of neuron destruction. This is especially concerning due to the limited capacity of the brain to regenerate neurons and oftentimes, the damage is permanent. Following a seizure, epileptic's brains often form excitotoxic lesions which destroy neurons by initiating apoptosis. The current treatment for epilepsy is limited to controlling the seizure activity. Anticonvulsants are oral medications used to prevent seizures in patients with epilepsy. The specific drug prescribed to patients 
varies based on their past seizure history and any underlying conditions that may have contributed to the epileptic diagnosis. (Prunetti and Perucca 2011; Steinert, Baier et al. 2011; Strzelczyk, Cenusa et al. 2011; Verrotti, Loiacono et al. 2011; Yasuda, Sugiura et al. 2011). In patients with epilepsy resulting from chronic infections, the epileptic symptoms will subside after the course of drug treatment. Also, epilepsy occurring after tumor development or following injury to blood vessels, such as a hematoma, can be successfully managed in some cases after the underlying cause of injury is treated. Nevertheless, it is difficult to treat these types of brain injuries; so many patients use proper medication to prevent the seizures (Sander 1993).

The cases of epilepsy that do not respond to medication (Go and Snead 2008; Berg 2009; Nakken and Tauboll 2009), are often candidates for invasive and risky procedures such as brain surgery. Surgery can remove the damaged cells of the brain which cause the abnormal electrical signals. Other surgical procedures such as implantation of a device, similar to a heart pacemaker, stimulate the vagal nerve and help reduce the frequency of seizures (Landre 2004). Unfortunately, there are also types of epilepsy that cannot be managed well with medication or any other available therapies and the general term for this type of epilepsy is called refractory or intractable epilepsy (Sander 1993; Kwan and Brodie 2000; Lerman, Sagie et al. 2011). Growing lines of evidence have indicated a role of inflammation in causing and exacerbating intractable epilepsy (Vezzani, French et al. 2011). Patients with intractable epilepsy often go on specialized diets which are thought to help reduce the severity and number of seizures. Popular diet choices for epileptic patients are diets low in carbohydrates, such as the ketogenic diet (Kossoff and McGrogan 2005), which is very low in carbohydrates and very high in fat but still calorie balanced for the individual. For undetermined reasons, when the body of an epileptic burns fat for fuel, rather than glucose, it can help control and prevent seizures (Baranano and Hartman 2008; Choragiewicz, Zarnowska et al. 2010; Westmark, Westmark et al. 2010). While the ketogenic diet is effective, long term health implications prevent patients from being on the diet for periods longer than two years (de Kinderen, Lambrechts et al. 2011). Dietary antioxidants are known to protect against seizures possibly by increasing the free radical scavenging capabilities of key antioxidant enzymes in the brain (Garjani, Fathiazad et al. 2009; Mehla, Reeta et al. 2010; Militao, Ferreira et al. 2010; Pages, Maurois et al. 2010; Sharma, Nehru et al. 2010; Tome Ada, Ferreira et al. 2010). Using a nutrigenomics approach to identify compounds with a beneficial effect (Suzuki 2011), researchers can identify genes associated with epilepsy susceptibility and then test whether particular dietary components, in this case selenium, can be used to improve the incidence, frequency, and severity of epilepsy and the resulting complications.

\section{Selenium and selenoproteins}

Selenium is a non-metal trace element discovered in 1817 as a by-product of sulfuric acid production (Brown and Arthur 2001). Selenium exists in nature in organic (such as selenomethionine and selenocysteine) or inorganic (such as selenate and selenite) forms (Puzanowska-Tarasiewicz, Kuzmicka et al. 2009).

Selenium can be incorporated non-specifically into methionone-rich proteins, such as those in the Brazil nut and sunflower seeds (Kortt, Caldwell et al. 1991). The biological functions of selenium are mainly mediated by selenoproteins, which contain selenocysteine (Allmang, Wurth et al. 2009; Lu and Holmgren 2009). Selenocysteine (Sec) has its own tRNA and its own 
codon, UGA (de Jesus, Hoffmann et al. 2006). Sec is inserted into mRNA in response to UGA codons in the genome of all selenoproteins. Selenoprotein mRNA is characterized by selenocysteine insertion sequence element (SECIS) (Howard, Moyle et al. 2007; Mix, Lobanov et al. 2007), and a RNA-binding protein complex (Bock, Forchhammer et al. 1991; SmallHoward and Berry 2005; Allmang and Krol 2006; Squires and Berry 2008). Some seleniumcontaining proteins such as the liver protein $56 \mathrm{~K}$ and the liver fatty acid binding protein (Behne, Weiss-Nowak et al. 1994) can sequester Se, but they do not contain selenocysteine.

Selenium was only recognized as a toxicant (Belogorsky and Slaughter 1949; Fels and Cheldelin 1949; Klug, Harshfield et al. 1952; Mc and Portman 1952; Fabre and Truhaut 1956) and its biological role was unknown until 1952 when its essential role was discovered in microorganisms. It is a trace mineral that is essential for humans (Papp, Lu et al. 2007), which was first recognized when when dietary supplementation of selenium prevented liver necrosis in rats efficiently (Mertz and Schwarz 1958; Schwarz, Stesney et al. 1959; Schwarz, Porter et al. 1972). Following these studies, it was found that selenium was essential for glutathione peroxidase (GPX) activity (Flohe, Gunzler et al. 1973; Rotruck, Pope et al. 1973). Sec, now identified as the $21^{\text {st }}$ amino acid was indentified in eubacteria and archaebacteria model systems (Ambrogelly, Palioura et al. 2007; Xu, Carlson et al. 2007). Stadtman and colleagues found that selenium was incorporated into proteins in the form of selenocysteine through labeled Clostridium sticklandii with ${ }^{75}$ Se metabolically (Cone, Del Rio et al. 1976; Axley and Stadtman 1989; Lee, Worland et al. 1989; Leinfelder, Stadtman et al. 1989; Stadtman, Davis et al. 1989). UGA, the stop codon, was discovered for selenocysteine incorporation in murine and GPX1 gene was cloned at the same time (Chambers, Frampton et al. 1986).

Selenium deficiency (Kakturskii, Strochkova et al. 1990), or Keshan disease, is responsible for the cardiomyopathy in children living in parts of China where the soil lacks selenium (Guanqing 1979; Yang and Xia 1995; Yang, Chen et al. 2007). Recently, the gene of Secisbp2 protein, which is related with synthesis of selenoproteins (Copeland and Driscoll 1999; Copeland, Fletcher et al. 2000; Low, Grundner-Culemann et al. 2000; Tujebajeva, Copeland et al. 2000; Berry, Tujebajeva et al. 2001; Copeland and Driscoll 2001; Copeland, Stepanik et al. 2001; Fletcher, Copeland et al. 2001; Copeland and Driscoll 2002; Lescure, Allmang et al. 2002; Lescure, Fagegaltier et al. 2002), has been studied as a possible target for hereditary diseases, an example of which includes human thyroid hormone metabolism disorder (Dumitrescu, Liao et al. 2005). Selenium is also known as an important chemoprevention agent (El-Sayed, Aboul-Fadl et al. 2006; Micke, Schomburg et al. 2009) by inducing apoptosis in cancer cells (Jackson and Combs 2008) and senescence in the early stage of tumorigenesis (Wu, Kang et al. 2010) in a dose-dependent manner.

More than 50 years ago, the ROS (reactive oxygen species) theory of aging was proposed. However, there is still there is a lack of irrefutable evidence in support or opposition of this theory. ROS can be induced by exogenous sources, such as UV or ionizing irradiation (Finkel 2000), which are by-products of mitochondrial respiration and widespread in vivo as the form of superoxides, hydroxyl free radicals, and hydrogen peroxides (Harman, 1956). As previous studies have shown, GPX1 contributes much of the $\mathrm{H}_{2} \mathrm{O}_{2}$-eliminating activity of selenium (Cheng, Ho et al. 1997; Cheng, Ho et al. 1997; Lei, Cheng et al. 2007). Therefore, it is logical to address the ROS theory of aging through investigation of selenium and selenoproteins (Hawkes and Alkan 2010). Some studies have implied that the accumulation of lipid oxidation in mitochondria has the potential to suppress the increased activity of GPX when comparing aged and juvenile rats (Nohl, Hegner et al. 1979). However, there is 
no conclusive evidence to identify the biological function of GPX1 in lifespan extension in mouse models (Ladiges, Van Remmen et al. 2009). Interestingly, GPX4/- mice are embryonic lethal while GPX4+/- mice displays lifespan extension (Ran, Liang et al. 2007).

Most of the selenoproteins that have been identified are enzymes with selenium in their active sites. Through scanning the whole human genome to find SECIS, a total of 25 selenoproteins were discovered (Kryukov, Castellano et al. 2003), which contain five glutathione peroxidases (GPX1-4, GPX6), three thioredoxin reductases (TR1-3) (Hondal and Ruggles 2010), three iodothyronine deiodinases (DI-III), the 15-kDa selenoprotein (Sep 15), selenophosphate synthetase-2 (SPS2), and selenoprotein $\mathrm{H}, \mathrm{I}, \mathrm{K}, \mathrm{M}, \mathrm{N}, \mathrm{O}, \mathrm{P}, \mathrm{R}, \mathrm{S}, \mathrm{T}, \mathrm{U}, \mathrm{V}$. All selenoproteins only have one selenocysteine residue except for selenoprotein $\mathrm{P}$ which contains 10 residues (Burk and Hill 1999). The domains containing selenocysteine residues in selenoprotein are highly related with their enzyme activities (Hill, Zhou et al. 2007). It was noted that cysteine replacing the selenocysteine residue in selenoproteins lead to reduction of catalytic activity (Hazebrouck, Camoin et al. 2000; Lee, Bar-Noy et al. 2000; Korotkov, Novoselov et al. 2002; Kryukov and Gladyshev 2002).

Notably, more than one-third of selenoproteins play a critical role in combating oxidative stress. The GPX family uses glutathione as a reducing equivalent to eliminate hydrogen peroxide, organic hydroperoxides and phospholipid hydroperoxides (Bosch-Morell, Flohe et al. 1999; Flohe, Hecht et al. 1999). The redox status of thioredoxin is under the control of the thioredoxin reductase (TR) family (Bjornstedt, Hamberg et al. 1995; Holmgren and Bjornstedt 1995). Sel P is thought to be not only a selenium carrier, which distributes in body fluids, but capable of eliminating phospholipid hydroperoxides (Saito, Hayashi et al. 1999; Takebe, Yarimizu et al. 2002). It is important to elucidate the mechanism by which selenoperoxidases eliminate ROS in the brain and to identify additional selenoperoxidases and their functions during aging and neuron degeneration.

\section{Selenium and selenoproteins in epilepsy}

The brain expresses most selenoproteins and is at the apex of selenium retention in the body (Nakayama, Hill et al. 2007). It is proposed that selenium may be necessary for prevention of epilepsy or other degenerative neurological disorders; however, there is no consensus in the field whether selenium plays a direct role or not. Selenium has a role in protection the neurons from excitotoxic insults, such as the continuous stimulation of a nerve cell by glutamate or another neurotransmitter, and thus can decrease the insult burden on the neurons (Savaskan, Brauer et al. 2003).

Although no severe neurological phenotypes have been associated with a selenium deficient diet, this may be due to the brain's preferential sequestration of body selenium. Mice on a selenium deficient diet are, however, more susceptible to neuropathological changes (Hill, Zhou et al. 2004). It is not well known how selenium status in the blood and the brain are correlated (Chen and Berry 2003), but it is known that selenium supplementation can prevent dopamine loss and degeneration of neurons in the substantia nigra, and reduce lipid peroxidation (Aldeeb, Almoutaery et al. 1995; Imam, Newport et al. 1999; Zafar, Siddiqui et al. 2003). Selenium was shown to protect the neurons through selenoproteins (Savaskan, Brauer et al. 2002; Lamarche, Signorini-Allibe et al. 2004; Reeves, Bellinger et al. 2010; Wang, Geng et al. 2010) and other studies that combine selenium treatment with anticonvulsant medication showed a synergistic protective effect against induced seizures (Kutluhan, Naziroglu et al. 2009). Also, in cases of selenium deficiency, neurons are exposed 
to increased glutamate-induced excitotoxicity because selenium has an inhibitory effect on the glutamate induced NF-kB and AP-1 activation (Savaskan, Brauer et al. 2002; Santamaria, Vazquez-Roman et al. 2005).

There are a total of 24 selenoproteins in mice, all of which are expressed in the brain, particularly in neurons of the olfactory bulb, hippocampus, cerebral cortex and cerebellar cortex (Zhang, Zhou et al. 2008). In these tissues Gpx4, Sel K, Sel M, Sel W, and Sel 15 mRNAs were expressed the most, but in the choroid plexus over half of the identified selenoproteins were expressed. Gpx4, Sel P, and Sel W genes were highly expressed in over $90 \%$ of the brain, similar to findings from previous studies that found Sel P and Sel W were highly expressed in the rodent brain (Dreher, Schmutzler et al. 1997; Steinert, Bachner et al. 1998; Sun, Butler et al. 2001; Hoffmann, Hoge et al. 2007; Nakayama, Hill et al. 2007; Renko, Hofmann et al. 2009).

There are some regions of the rodent brain that express significantly lower levels of selenoproteins, which implies that some structures of the brain are less dependent on selenium availability. Selenoprotein genes are expressed the lowest in the oculomotor nucleus, Edinger-Westphal nucleus, nucleus Raphé pontis, anteroventral periventricular nucleus and dorsal premammillary nucleus; however, these brain regions do express the same selenoproteins that are found to be highly expressed in other regions of the brain, but at a significantly lower level, such as Sel P, and Sel W and Gpx 4 (Zhang, Zhou et al. 2008). In the white matter of the brain, or corpus callosum, selenoprotein expression is considerably less than in other regions of the brain. The corpus collosum consists of mainly myelinated axons and is responsible for carrying the nerve impulses to different regions of gray matter. Generation of ROS and the resulting oxidative stress are known to be both the cause and consequence of many neurodegenerative conditions (Sander 1993). Post mortem autopsies of people with the neurodegenerative disorders Parkinson's disease, Alzheimer's disease, and amyotrophic lateral sclerosis all show that there are increased ROS in the regions of the brains that were affected by the neurodegenerative disorder. The brain has a reduced capacity for regeneration and a high metabolic rate which predisposes it to oxidative damage. The repair mechanisms that the cells have employed to counteract oxidative damage are primarily antioxidant enzymes such as glutathione peroxidases and thioredoxin reductases which are dependent on selenium for their function. Accumulating lines of evidence suggest that selenium-dependent antioxidant enzymes and selenoproteins are integral to epilepsy and have a role in the progression of the disease. It is promising to use selenium as a line of treatment against degenerative free radical diseases such as epilepsy.

\subsection{The Se-dependent glutathione peroxidase}

The function of the GPX family is to remove hydrogen and other peroxides from the brain and other tissues by coupling its reduction to water and alcohols using glutathione as a reducing equivalent. Glutathione is found in the mitochondria and cytoplasm of brain tissue and has been found to be released into the extracellular space by astrocytes. Interestingly, the first report of selenium status affecting any neurological condition was in infants with intractable epilepsy (Weber, Maertens et al. 1991). Infant brains are particularly susceptible to oxidative damage, which can contribute to abnormal brain electrical signaling, because of the high concentration of unsaturated fatty acids in the infant brain needed to synthesize cholesterol and fatty acids. These nutrients are necessary for the billions of developing nerve connections. 
The seizure symptoms of these infants can be reversed with selenium supplementation (Weber, Maertens et al. 1991; Ramaekers, Calomme et al. 1994). Children suffering from intractable epilepsy are deficient in glutathione peroxidase activity. From the four children studied, two had normal blood selenium and high concentrations of GPX in their plasma, but low enzymatic activity. The other children had low intracellular selenium levels and low GPX expression and activity. Selenium supplementation and discontinuation of their anticonvulsant medication decreased seizure activity. The second study found that oral selenium supplements in children (3-5 $\mu \mathrm{g} / \mathrm{kg}$ body weight) decreased frequency of seizures, improved electroencephalograph recordings, and restored liver function in the infants after two weeks of treatment (Ramaekers, Calomme et al. 1994). It was thought that supplementation of selenium restored the function of selenium-dependent GPX1 and GPX4 activity. From these results, selenium status is an important triggering factor for the onset of intractable seizures and that selenium-conferred antioxidant protection in the brain can help prevent neuronal damage following frequent seizures.

It has been suggested that treatment with anticonvulsants, such as valproic acid, which induces oxidative stress, depletes total body selenium and decreases GPX activity (Naziroglu 2009). However, others believe that selenium supplementation in congruence with antiepileptic drugs increase the risk of systemic toxicity. The conflicting selenium levels are likely associated with the pharmacology of the particular drug, duration of treatment, age of subject, validity of plasma selenium estimating brain selenium concentrations, and the underlying cause of the patient's epilepsy. It has been found that epileptic patients, without medication, have lower blood and tissue levels of selenium in addition to lower levels of selenoproteins and lower levels of selenium-dependent redox enzymes. In particular, intractable epileptics have been shown to have significantly lower mean serum selenium levels compared to a control group (Ashrafi, Shabanian et al. 2007). Animal models have shown that selenium can prevent the development of iron-induced epileptic symptoms due to selenium's ability to combat peroxidative injury (Rubin and Willmore 1980; Willmore and Rubin 1981).

\subsection{Thioredoxin reductases}

Thioredoxin reductases (TR) use NADPH for reduction of thioredoxin in various cellular redox pathways (Tamura and Stadtman 2002). TR-3 is expressed in very low levels in the mouse brain (Zhang, Zhou et al. 2008). Although TR-1 is well characterized and expressed in high levels in other organs, it is not highly expressed in the brain. Since TR is important for intracellular redox regulation and antioxidant defense (Schweizer, Brauer et al. 2004), decreased TR expression and activities could lead to enhanced cell loss, thus increasing the risk for epilepsy and other neurodegenerative conditions.

\subsection{Selenoprotein $\mathbf{P}$}

Selenoprotein P (Sel P) is unique because it contains 10-17 selenocysteine residues, unlike other selenoproteins which contain only one. Sel $\mathrm{P}$ is produced mostly in the liver, but all tissues make and secrete Sel P into the plasma (Burk and Hill 2005; Hoffmann, Hoge et al. 2007). In rodents, Sel P is a predominant form of selenium in the plasma. Sel P is responsible for selenium transportation throughout the body, particularly to the brain where selenium is needed for incorporation into other selenoproteins which confer antioxidant benefits (Hill, Zhou et al. 2007). Sel P knockout mice develop seizures and movement disorders when raised on selenium restricted diets. 
During seizure activity in epileptics, the neurons in the affected areas of the brain often have redox shifts due to the large influx of calcium through voltage gated channels (Stefani, Spadoni et al. 1997). If cellular redox equilibrium is not quickly restored following seizures, it is probable that the neurons will die and that region of the brain will be unable to function properly (Wirth, Conrad et al. 2010). It is thought that selenium, probably through its function in the GPX or TR families, can help prevent neuronal cell death and neutralize ROS which is generated as a consequence of high intracellular calcium (Xiong, Markesbery et al. 2007). Typically the brain can handle redox shifts and occasional electrolyte imbalances; however, during a seizure these activities happen at a rate and frequency that the cells cannot handle (Howse and Duffy 1975). The neurons eventually will die, and cause an increase in potentially harmful cellular byproducts (Barinaga 1998).

\subsection{Selenoprotein W}

Selenoprotein W (Sel W) has a redox motif and binds glutathione (Beilstein, Vendeland et al. 1996; Whanger 2009), similar to the well characterized GPX family. The 'W' designation is because of the white muscle disease seen in grazing livestock in areas where the soil is depleted of selenium (Vendeland, Beilstein et al. 1993). Sel W is highly expressed in the four basic brain regions in rodents; the hippocampus, olfactory area, cerebellar cortex, and isocortex (Zhang, Zhou et al. 2008).

The expression of Sel W is induced in the neurons of mesial temporal lobe epilepsy patients more than tenfold and is associated with BCL2 expression, which suggests that the Sel W induction is a defensive response to oxidative stress (Yuzbasioglu, Karatas et al. 2009). Furthermore, the expression of Sel W in cortex, cerebellum, and thalamus remains constant under Se deficiency (Sun et al., 2001b). Thus, Sel W expression is maintained in certain regions of the brain under selenium deficiency, suggesting a critical role of Sel $W$ in the protection against seizure activities that is associated with increased oxidative stress.

\subsection{Selenoprotein $\mathrm{H}$}

Selenoprotein H (Sel H) is a nucleolar DNA-binding protein (Novoselov, Kryukov et al. 2007) and may function as a transcription factor (Panee, Stoytcheva et al. 2007). It has been found that Sel H mRNA is highly expressed in the hippocampus during development but level falls quickly after birth and is undetectable in the adult brain (Zhang, Zhou et al. 2008); however, in another study the Sel H gene was found to be expressed in the adult mouse brain by using the RT-PCR method (Hoffmann, Hoge et al. 2007).

\subsection{Selenoprotein $\mathbf{M}$}

Selenoprotein M (Sel M) is a small endoplasmic reticulum protein with unknown function, which is highly expressed in cornu ammonis granule cells of dentate gyrus (Zhang, Zhou et al. 2008). Cornu ammonis is also known as Ammon's horn and is part of the interlocking gyri which makes up the hippocampus. Interestingly, the most common form of neuropathological damage in temporal lobe epilepsy patients is sclerosis (hardening of tissue) of the cornu ammonis, also known as Ammon's horn sclerosis, which is characterized by neuronal cell loss in the hippocampus region of the brain. Common clinical markers of the disease include granule cell dispersion, reactive gliosis, and the segmental loss of pyramidal neurons. Unfortunately, $65 \%$ of people with temporal lobe epilepsy suffer from this disease (Blumcke, Thom et al. 2002; de Lanerolle and Lee 2005). Many of the seizures 
due to temporal lobe epilepsy are very poorly controlled with anticonvulsant drugs. The role of Sel M is not fully understood and it is unclear whether Ammon's horn sclerosis is the cause of seizures of epileptics, or rather damage from the ongoing seizure activity.

\section{Selenium and neurological disorders}

Most inherited or congenital forms of epilepsy develop and occur before the age of 2. Older adults who have developed epilepsy have done so mostly because of brain injuries (hematomas and other bleeding vessels) or after a stroke. Generally, the most common cause of epilepsy in the elderly is attributed to cerebrovascular diseases or prescription drug reactions. Older populations are more at risk for drugs causing epileptiform activities because of their increased sensitivity to all drugs due to decreased drug metabolism.

Also other diseases in the elderly, particularly those that cause impaired language function or overall neurological deterioration, have been associated with increased seizure risks. Other factors such as metabolic problems, uraemia, thyroid problems, low blood sugar, electrolyte imbalances and liver damage can all contribute to seizures in the older population. In addition to the metabolic risk factors, epilepsy risk can also increase in patients with neurological disorders such as Alzheimer's (Noebels 2011), down syndrome, and dementia (Ito, Echizenya et al. 2009; Palop and Mucke 2009; Rao, Dove et al. 2009; Scarmeas, Honig et al. 2009; Larner 2010; Westmark, Westmark et al. 2010).

There is a link between neurological disorders and aging (Zhang, Rocourt et al. 2010). Since the body preferentially retains selenium in the brain even during periods of selenium deficiency, which further implies that selenium plays an important role in the brain (Behne, Hilmert et al. 1988; Chen and Berry 2003). Neurological disorders such as Alzheimer's disease, Parkinson's disease, and those disease states resulting from damage caused by environmental toxins, ischemic insults, drug abuse, and brain tumors are exacerbated by ROS (Chen and Berry 2003).

The selenium protection against neurological disorders is primarily conferred through antioxidative selenoproteins (Zhang, Rocourt et al. 2010). Therefore, selenoproteins play an important role in regulating redox reactions in the body, and particularly the brain. For example, the brains in mouse models of Alzheimer's disease show reduced levels of Sel M, which could mean that this selenoprotein plays a protective role in the development of Alzheimer's disease (Hwang, Cho et al. 2005).

Sel $\mathrm{P}$ knockout mice have movement disorders and seizures when given selenium-restricted diets from their birth (Hill, Zhou et al. 2003; Schomburg, Schweizer et al. 2003; Kutluhan, Naziroglu et al. 2009). Rats on selenium deficient diets have an increased risk of seizures and neuronal loss, further providing evidence that selenium can help prevent seizures. Because epilepsy is characterized by neuronal loss resulting from pro-apoptotic factors in association with oxidative stress (Savaskan, Brauer et al. 2003), selenium might help alleviate the underlying causes of brain injury that precipitate seizures.

\section{Nutrigenomics perspectives}

There is much evidence that speculates on the genetic aspect of epilepsy (Rees 2010; Sisodiya and Mefford 2011). Nonetheless, since epilepsy is a syndrome and not a disease, the cause of seizures in epileptics varies widely. Furthermore, even if epilepsy could be divided into groups based on the respective, underlying cause, it would still be difficult to determine the 
genetic influence because of changes across clinical subgroups and amongst families. However, some types of epilepsy have been shown to have strong genetic components (Greenberg and Subaran 2011): 1) partial epilepsy has been linked to chromosome $10 \mathrm{q} ; 2$ ) benign familial neonatal convulsions have been mapped to chromosome $20 \mathrm{q}$ and another locus found on $8 \mathrm{q}$; 3) a progressive form of myoclonus epilepsy has been localized to chromosome $21 \mathrm{q}$; 4) juvenile myoclonic epilepsy has been associated with regions of chromosome 6. Interestingly, the types of epilepsy syndromes that have genetic linkage evidence are a very small proportion of all epilepsy cases and no genetic basis has been found for most types of epilepsy.

Nutrigenomics is the study of how nutrition impacts the variation of gene expression across individuals. Seeing as how genetically diverse individuals are, it would stand to reason that individualized diets based on a person's genetic background can contribute to better overall health. Nutrigenomic approaches will become increasingly necessary in treating chronic diseases, including epilepsy. In the future it is expected that we will uncover genetic evidence that explains why certain people have different responses to similar diet, and how such variations help alleviate neuronal disorders.

\section{References}

Aldeeb, S., K. Almoutaery, et al. (1995). "Neuroprotective Effect of Selenium on Iminodipropionitrile-Induced Toxicity." Journal of Psychiatry \& Neuroscience 20(3): 189-192.

Allmang, C. and A. Krol (2006). "Selenoprotein synthesis: UGA does not end the story." Biochimie 88(11): 1561-71.

Allmang, C., L. Wurth, et al. (2009). "The selenium to selenoprotein pathway in eukaryotes: more molecular partners than anticipated." Biochim Biophys Acta 1790(11): 141523.

Ambrogelly, A., S. Palioura, et al. (2007). "Natural expansion of the genetic code." Nat Chem Biol 3(1): 29-35.

Ashrafi, M. R., R. Shabanian, et al. (2007). "Selenium and intractable epilepsy: Is there any correlation?" Pediatric Neurology 36(1): 25-29.

Axley, M. J. and T. C. Stadtman (1989). "Selenium metabolism and selenium-dependent enzymes in microorganisms." Annu Rev Nutr 9: 127-37.

Baranano, K. W. and A. L. Hartman (2008). "The ketogenic diet: uses in epilepsy and other neurologic illnesses." Curr Treat Options Neurol 10(6): 410-9.

Barinaga, M. (1998). "Stroke-damaged neurons may commit cellular suicide." Science 281(5381): 1302-3.

Behne, D., H. Hilmert, et al. (1988). "Evidence for specific selenium target tissues and new biologically important selenoproteins." Biochim Biophys Acta 966(1): 12-21.

Behne, D., C. Weiss-Nowak, et al. (1994). "Application of nuclear analytical methods in the investigation and identification of new selenoproteins." Biol Trace Elem Res 43-45: 287-97.

Beilstein, M. A., S. C. Vendeland, et al. (1996). "Selenoprotein W of rat muscle binds glutathione and an unknown small molecular weight moiety." J Inorg Biochem 61(2): 117-24.

Belogorsky, J. B. and D. Slaughter (1949). "Administration of BAL in selenium poisoning." Proc Soc Exp Biol Med 72(1): 196-8. 
Berg, A. T. (2009). "Identification of pharmacoresistant epilepsy." Neurol Clin 27(4): 1003-13.

Berg, A. T. and M. M. Kelly (2006). "Defining intractability: comparisons among published definitions." Epilepsia 47(2): 431-6.

Bergen, D. C. (1998). "Preventable neurological diseases worldwide." Neuroepidemiology 17(2): 67-73.

Berry, M. J., R. M. Tujebajeva, et al. (2001). "Selenocysteine incorporation directed from the 3'UTR: characterization of eukaryotic EFsec and mechanistic implications." Biofactors 14(1-4): 17-24.

Bjornstedt, M., M. Hamberg, et al. (1995). "Human thioredoxin reductase directly reduces lipid hydroperoxides by NADPH and selenocystine strongly stimulates the reaction via catalytically generated selenols." Journal of Biological Chemistry 270(20): 11761-4.

Blumcke, I., M. Thom, et al. (2002). "Ammon's horn sclerosis: a maldevelopmental disorder associated with temporal lobe epilepsy." Brain Pathol 12(2): 199-211.

Bock, A., K. Forchhammer, et al. (1991). "Selenocysteine: the 21st amino acid." Mol Microbiol 5(3): 515-20.

Bosch-Morell, F., L. Flohe, et al. (1999). "4-Hydroxynonenal inhibits glutathione peroxidase: protection by glutathione." Free Radic Biol Med 26(11-12): 1383-7.

Brown, K. M. and J. R. Arthur (2001). "Selenium, selenoproteins and human health: a review." Public Health Nutr 4(2B): 593-9.

Burk, R. F. and K. E. Hill (1999). "Orphan selenoproteins." Bioessays 21(3): 231-7.

Burk, R. F. and K. E. Hill (2005). "Selenoprotein P: an extracellular protein with unique physical characteristics and a role in selenium homeostasis." Annu Rev Nutr 25: 215-35.

Chambers, I., J. Frampton, et al. (1986). "The structure of the mouse glutathione peroxidase gene: the selenocysteine in the active site is encoded by the 'termination' codon, TGA." EMBO J 5(6): 1221-7.

Chen, J. and M. J. Berry (2003). "Selenium and selenoproteins in the brain and brain diseases." Journal of Neurochemistry 86(1): 1-12.

Cheng, W. H., Y. S. Ho, et al. (1997). "Overexpression of cellular glutathione peroxidase does not affect expression of plasma glutathione peroxidase or phospholipid hydroperoxide glutathione peroxidase in mice offered diets adequate or deficient in selenium." Journal of Nutrition 127(5): 675-80.

Cheng, W. H., Y. S. Ho, et al. (1997). "Cellular glutathione peroxidase knockout mice express normal levels of selenium-dependent plasma and phospholipid hydroperoxide glutathione peroxidases in various tissues." Journal of Nutrition 127(8): 1445-50.

Choragiewicz, T., I. Zarnowska, et al. (2010). "[Anticonvulsant and neuroprotective effects of the ketogenic diet]." Przegl Lek 67(3): 205-12.

Cone, J. E., R. M. Del Rio, et al. (1976). "Chemical characterization of the selenoprotein component of clostridial glycine reductase: identification of selenocysteine as the organoselenium moiety." Proc Natl Acad Sci U S A 73(8): 2659-63.

Copeland, P. R. and D. M. Driscoll (1999). "Purification, redox sensitivity, and RNA binding properties of SECIS-binding protein 2, a protein involved in selenoprotein biosynthesis." Journal of Biological Chemistry 274(36): 25447-54.

Copeland, P. R. and D. M. Driscoll (2001). "RNA binding proteins and selenocysteine." Biofactors 14(1-4): 11-6. 
Copeland, P. R. and D. M. Driscoll (2002). "Purification and analysis of selenocysteine insertion sequence-binding protein 2." Methods Enzymol 347: 40-9.

Copeland, P. R., J. E. Fletcher, et al. (2000). "A novel RNA binding protein, SBP2, is required for the translation of mammalian selenoprotein mRNAs." EMBO J 19(2): 306-14.

Copeland, P. R., V. A. Stepanik, et al. (2001). "Insight into mammalian selenocysteine insertion: domain structure and ribosome binding properties of Sec insertion sequence binding protein 2." Mol Cell Biol 21(5): 1491-8.

de Jesus, L. A., P. R. Hoffmann, et al. (2006). "Nuclear assembly of UGA decoding complexes on selenoprotein mRNAs: a mechanism for eluding nonsense-mediated decay?" Mol Cell Biol 26(5): 1795-805.

de Kinderen, R. J., D. A. Lambrechts, et al. (2011). "Research into the (Cost-) effectiveness of the ketogenic diet among children and adolescents with intractable epilepsy: design of a randomized controlled trial." BMC Neurol 11(1): 10.

de Lanerolle, N. C. and T. S. Lee (2005). "New facets of the neuropathology and molecular profile of human temporal lobe epilepsy." Epilepsy Behav 7(2): 190-203.

Dreher, I., C. Schmutzler, et al. (1997). "Expression of selenoproteins in various rat and human tissues and cell lines." Journal of Trace Elements in Medicine and Biology 11(2): 83-91.

Dumitrescu, A. M., X. H. Liao, et al. (2005). "Mutations in SECISBP2 result in abnormal thyroid hormone metabolism." Nat Genet 37(11): 1247-52.

El-Sayed, W. M., T. Aboul-Fadl, et al. (2006). "Effect of selenium-containing compounds on hepatic chemoprotective enzymes in mice." Toxicology 220(2-3): 179-88.

Fabre, R. and R. Truhaut (1956). "Toxicological study of selenium." Rev Pathol Gen Physiol Clin 56(675): 323-39.

Farrell, K., E. Wirrell, et al. (2006). "The definition and prediction of intractable epilepsy in children." Adv Neurol 97: 435-42.

Fels, I. G. and V. H. Cheldelin (1949). "Selenate inhibition studies; the role of sulfate in selenate toxicity in yeast." Arch Biochem 22(3): 402-5.

Feng, Y. K. (1978). "Some statistics on 2,810 cases of epilepsy." Chin Med J (Engl) 4(6): 449-56.

Finkel, T. (2000). "Redox-dependent signal transduction." FEBS Lett 476(1-2): 52-4.

Fisher, R. S., W. van Emde Boas, et al. (2005). "Epileptic seizures and epilepsy: definitions proposed by the International League Against Epilepsy (ILAE) and the International Bureau for Epilepsy (IBE)." Epilepsia 46(4): 470-2.

Fletcher, J. E., P. R. Copeland, et al. (2001). "The selenocysteine incorporation machinery: interactions between the SECIS RNA and the SECIS-binding protein SBP2." RNA 7(10): 1442-53.

Flohe, L., W. A. Gunzler, et al. (1973). "Glutathione peroxidase: a selenoenzyme." FEBS Lett 32(1): 132-4.

Flohe, L., H. J. Hecht, et al. (1999). "Glutathione and trypanothione in parasitic hydroperoxide metabolism." Free Radic Biol Med 27(9-10): 966-84.

Fountain, N. B., P. C. Van Ness, et al. (2011). "Quality improvement in neurology: AAN epilepsy quality measures: Report of the Quality Measurement and Reporting Subcommittee of the American Academy of Neurology." Neurology 76(1): 94-9.

Garjani, A., F. Fathiazad, et al. (2009). "The effect of total extract of Securigera securidaca L. seeds on serum lipid profiles, antioxidant status, and vascular function in hypercholesterolemic rats." J Ethnopharmacol 126(3): 525-32. 
Go, C. and O. C. Snead, 3rd (2008). "Pharmacologically intractable epilepsy in children: diagnosis and preoperative evaluation." Neurosurg Focus 25(3): E2.

Gomez-Alonso, J. and B. G. Giraldez (2007). "Epilepsy: a new definition for an old disease." Rev Neurol 45(2): 126-7.

Greenberg, D. A. and R. Subaran (2011). "Blinders, phenotype, and fashionable genetic analysis: a critical examination of the current state of epilepsy genetic studies." Epilepsia 52(1): 1-9.

Guanqing, H. (1979). "On the etiology of Keshan disease: two hypotheses." Chin Med J (Engl) 92(6): 416-22.

Haut, S. R., R. B. Lipton, et al. (2005). "Identifying seizure clusters in patients with epilepsy." Neurology 65(8): 1313-5.

Hawkes, W. C. and Z. Alkan (2010). "Regulation of redox signaling by selenoproteins." Biol Trace Elem Res 134(3): 235-51.

Hazebrouck, S., L. Camoin, et al. (2000). "Substituting selenocysteine for catalytic cysteine 41 enhances enzymatic activity of plant phospholipid hydroperoxide glutathione peroxidase expressed in Escherichia coli." Journal of Biological Chemistry 275(37): 28715-21.

Hill, K. E., J. Zhou, et al. (2007). "The selenium-rich C-terminal domain of mouse selenoprotein $\mathrm{P}$ is necessary for the supply of selenium to brain and testis but not for the maintenance of whole body selenium." Journal of Biological Chemistry 282(15): 10972-80.

Hill, K. E., J. Zhou, et al. (2003). "Deletion of selenoprotein P alters distribution of selenium in the mouse." Journal of Biological Chemistry 278(16): 13640-6.

Hill, K. E., J. Zhou, et al. (2004). "Neurological dysfunction occurs in mice with targeted deletion of the selenoprotein P gene." Journal of Nutrition 134(1): 157-61.

Hoffmann, P. R., S. C. Hoge, et al. (2007). "The selenoproteome exhibits widely varying, tissue-specific dependence on selenoprotein P for selenium supply." Nucleic Acids Research 35(12): 3963-73.

Hoffmann, P. R., S. C. Hoge, et al. (2007). "The selenoproteome exhibits widely varying, tissue-specific dependence on selenoprotein P for selenium supply." Nucleic Acids Research 35(12): 3963-3973.

Holmgren, A. and M. Bjornstedt (1995). "Thioredoxin and thioredoxin reductase." Methods Enzymol 252: 199-208.

Hondal, R. J. and E. L. Ruggles (2011). "Differing views of the role of selenium in thioredoxin reductase." Amino Acids 41(1):73-89.

Howard, M. T., M. W. Moyle, et al. (2007). "A recoding element that stimulates decoding of UGA codons by Sec tRNA[Ser]Sec." RNA 13(6): 912-20.

Howse, D. C. and T. E. Duffy (1975). "Control of the redox state of the pyridine nucleotides in the rat cerebral cortex. Effect of electroshock-induced seizures." J Neurochem 24(5): 935-40.

Hwang, D. Y., J. S. Cho, et al. (2005). "Differentially expressed genes in transgenic mice carrying human mutant presenilin-2 (N141I): correlation of selenoprotein M with Alzheimer's disease." Neurochem Res 30(8): 1009-19.

Imam, S. Z., G. D. Newport, et al. (1999). "Selenium, an antioxidant, protects against methamphetamine-induced dopaminergic neurotoxicity." Brain Research 818(2): 575-578. 
Ito, M., N. Echizenya, et al. (2009). "A case series of epilepsy-derived memory impairment resembling Alzheimer disease." Alzheimer Dis Assoc Disord 23(4): 406-9.

Jackson, M. I. and G. F. Combs, Jr. (2008). "Selenium and anticarcinogenesis: underlying mechanisms." Curr Opin Clin Nutr Metab Care 11(6): 718-26.

Jaseja, H. (2009). "Definition of epilepsy: significance of its revision on clinical neurophysiological basis to improve prognosis and quality of life of patients with epilepsy." Med Hypotheses 72(6): 756-7.

Kakturskii, L. V., L. S. Strochkova, et al. (1990). "Hyposelenoses." Arkh Patol 52(12): 3-8.

Klug, H. L., R. D. Harshfield, et al. (1952). "Methionine and selenium toxicity." Journal of Nutrition 48(4): 409-20.

Korotkov, K. V., S. V. Novoselov, et al. (2002). "Mammalian selenoprotein in which selenocysteine (Sec) incorporation is supported by a new form of Sec insertion sequence element." Mol Cell Biol 22(5): 1402-11.

Kortt, A. A., J. B. Caldwell, et al. (1991). "Amino acid and cDNA sequences of a methioninerich $2 S$ protein from sunflower seed (Helianthus annuus L.)." Eur J Biochem 195(2): 329-34.

Kossoff, E. H. and J. R. McGrogan (2005). "Worldwide use of the ketogenic diet." Epilepsia 46(2): 280-9.

Kryukov, G. V., S. Castellano, et al. (2003). "Characterization of mammalian selenoproteomes." Science 300(5624): 1439-43.

Kryukov, G. V. and V. N. Gladyshev (2002). "Mammalian selenoprotein gene signature: identification and functional analysis of selenoprotein genes using bioinformatics methods." Methods Enzymol 347: 84-100.

Kutluhan, S., M. Naziroglu, et al. (2009). "Effects of selenium and topiramate on lipid peroxidation and antioxidant vitamin levels in blood of pentylentetrazol-induced epileptic rats." Biol Trace Elem Res 129(1-3): 181-9.

Kwan, P. and M. J. Brodie (2000). "Early identification of refractory epilepsy." New England Journal of Medicine 342(5): 314-319.

Ladiges, W., H. Van Remmen, et al. (2009). "Lifespan extension in genetically modified mice." Aging Cell 8(4): 346-52.

Lamarche, F., N. Signorini-Allibe, et al. (2004). "Influence of vitamin E, sodium selenite, and astrocyte-conditioned medium on neuronal survival after chronic exposure to ethanol." Alcohol 33(2): 127-38.

Landre, E. (2004). "[Vagus nerve stimulation and refractory partial epilepsies]." Rev Neurol (Paris) 160 Spec No 1: 5S280-7.

Larner, A. J. (2010). "Epileptic seizures in AD patients." Neuromolecular Med 12(1): 71-7.

Lee, B. J., P. J. Worland, et al. (1989). "Identification of a selenocysteyl-tRNA(Ser) in mammalian cells that recognizes the nonsense codon, UGA." Journal of Biological Chemistry 264(17): 9724-7.

Lee, S. R., S. Bar-Noy, et al. (2000). "Mammalian thioredoxin reductase: oxidation of the Cterminal cysteine/selenocysteine active site forms a thioselenide, and replacement of selenium with sulfur markedly reduces catalytic activity." Proc Natl Acad Sci U S A 97(6): 2521-6.

Lei, X. G., W. H. Cheng, et al. (2007). "Metabolic regulation and function of glutathione peroxidase-1." Annu Rev Nutr 27: 41-61. 
Leinfelder, W., T. C. Stadtman, et al. (1989). "Occurrence in vivo of selenocysteyltRNA(SERUCA) in Escherichia coli. Effect of sel mutations." Journal of Biological Chemistry 264(17): 9720-3.

Lerman, P., S. Sagie, et al. (2011). "Why can seizures remain intractable? Clinical vignettes from the life experience of a pediatric epileptologist." J Child Neurol 26(1): 121-5.

Lescure, A., C. Allmang, et al. (2002). "cDNA cloning, expression pattern and RNA binding analysis of human selenocysteine insertion sequence (SECIS) binding protein 2." Gene 291(1-2): 279-85.

Lescure, A., D. Fagegaltier, et al. (2002). "Protein factors mediating selenoprotein synthesis." Curr Protein Pept Sci 3(1): 143-51.

Low, S. C., E. Grundner-Culemann, et al. (2000). "SECIS-SBP2 interactions dictate selenocysteine incorporation efficiency and selenoprotein hierarchy." EMBO J 19(24): 6882-90.

Lu, J. and A. Holmgren (2009). "Selenoproteins." Journal of Biological Chemistry 284(2): 7237.

Maganti, R., P. Gerber, et al. (2008). "Nonconvulsive status epilepticus." Epilepsy Behav 12(4): 572-86.

Maillard, L., J. P. Vignal, et al. (2009). "Risk of epilepsy after a first epileptic seizure in adults: Can we predict the future?." Rev Neurol (Paris) 165(10): 782-8.

Mc, C. K. and O. W. Portman (1952). "Toxicity of dimethyl selenide in the rat and mouse." Proc Soc Exp Biol Med 79(2): 230-1.

Mehla, J., K. H. Reeta, et al. (2010). "Protective effect of curcumin against seizures and cognitive impairment in a pentylenetetrazole-kindled epileptic rat model." Life Sci 87(19-22): 596-603.

Meinardi, H., R. A. Scott, et al. (2001). "The treatment gap in epilepsy: the current situation and ways forward." Epilepsia 42(1): 136-49.

Mertz, W. and K. Schwarz (1958). "Reversal of respiratory decline in necrotic liver degeneration by intraportal antioxidants." Proc Soc Exp Biol Med 98(4): 808-12.

Micke, O., L. Schomburg, et al. (2009). "Selenium in oncology: from chemistry to clinics." Molecules 14(10): 3975-88.

Militao, G. C., P. M. Ferreira, et al. (2010). "Effects of lipoic acid on oxidative stress in rat striatum after pilocarpine-induced seizures." Neurochem Int 56(1): 16-20.

Mix, H., A. V. Lobanov, et al. (2007). "SECIS elements in the coding regions of selenoprotein transcripts are functional in higher eukaryotes." Nucleic Acids Research 35(2): 41423.

Nakayama, A., K. E. Hill, et al. (2007). "All regions of mouse brain are dependent on selenoprotein P for maintenance of selenium." Journal of Nutrition 137(3): 690-693.

Nakken, K. O. and E. Tauboll (2009). "Drug-resistant epilepsy." Tidsskr Nor Laegeforen 129(19): 1986-9.

Naziroglu, M. (2009). "Role of Selenium on Calcium Signaling and Oxidative Stress-induced Molecular Pathways in Epilepsy." Neurochem Res 34(12):2181-91.

Noebels, J. (2011). "A perfect storm: Converging paths of epilepsy and Alzheimer's dementia intersect in the hippocampal formation." Epilepsia 52 Suppl (1): 39-46.

Nohl, H., D. Hegner, et al. (1979). "Responses of mitochondrial superoxide dismutase, catalase and glutathione peroxidase activities to aging." Mech Ageing Dev 11(3): $145-51$. 
Novoselov, S. V., G. V. Kryukov, et al. (2007). "Selenoprotein H is a nucleolar thioredoxinlike protein with a unique expression pattern." Journal of Biological Chemistry 282(16): 11960-8.

Pages, N., P. Maurois, et al. (2010). "Activities of alpha-asarone in various animal seizure models and in biochemical assays might be essentially accounted for by antioxidant properties." Neurosci Res 68(4): 337-44.

Palop, J. J. and L. Mucke (2009). "Epilepsy and cognitive impairments in Alzheimer disease." Arch Neurol 66(4): 435-40.

Panee, J., Z. R. Stoytcheva, et al. (2007). "Selenoprotein H is redox-sensing high mobility group family DNA-binding protein that up-regulates genes involved in glutathione synthesis and phase II detoxification." Journal of Biological Chemistry 282(33): 23759-23765.

Papp, L. V., J. Lu, et al. (2007). "From selenium to selenoproteins: synthesis, identity, and their role in human health." Antioxid Redox Signal 9(7): 775-806.

Poduri, A. and D. Lowenstein (2011). "Epilepsy genetics-past, present, and future." Curr Opin Genet Dev 21(3):325-32.

Prunetti, P. and E. Perucca (2011). "New and forthcoming anti-epileptic drugs." Curr Opin Neurol 24(2): 159-64.

Puzanowska-Tarasiewicz, H., L. Kuzmicka, et al. (2009). "Biological function of some elements and their compounds. II. Selenium, selenate, selenium organic compounds." Pol Merkur Lekarski 27(159): 249-52.

Ramaekers, V. T., N. Calomme, et al. (1994). "Selenium Deficiency Triggering Intractable Seizures." Neuropediatrics 25(4): 217-223.

Ran, Q., H. Liang, et al. (2007). "Reduction in glutathione peroxidase 4 increases life span through increased sensitivity to apoptosis." J Gerontol A Biol Sci Med Sci 62(9): 93242.

Rao, S. C., G. Dove, et al. (2009). "Recurrent seizures in patients with dementia: frequency, seizure types, and treatment outcome." Epilepsy Behav 14(1): 118-20.

Rees, M. I. (2010). "The genetics of epilepsy--the past, the present and future." Seizure 19(10): 680-3.

Reeves, M. A., F. P. Bellinger, et al. (2010). "The neuroprotective functions of selenoprotein $\mathrm{M}$ and its role in cytosolic calcium regulation." Antioxid Redox Signal 12(7): 809-18.

Renko, K., P. J. Hofmann, et al. (2009). "Down-regulation of the hepatic selenoprotein biosynthesis machinery impairs selenium metabolism during the acute phase response in mice." Faseb Journal 23(6): 1758-1765.

Rotruck, J. T., A. L. Pope, et al. (1973). "Selenium: biochemical role as a component of glutathione peroxidase." Science 179(73): 588-90.

Rubin, J. J. and L. J. Willmore (1980). "Prevention of Iron-Induced Epileptiform Discharges in Rats by Treatment with Anti-Peroxidants." Experimental Neurology 67(3): 472-480.

Saito, Y., T. Hayashi, et al. (1999). "Selenoprotein P in human plasma as an extracellular phospholipid hydroperoxide glutathione peroxidase. Isolation and enzymatic characterization of human selenoprotein p." Journal of Biological Chemistry 274(5): 2866-71.

Sander, J. W. A. S. (1993). "Some Aspects of Prognosis in the Epilepsies - a Review." Epilepsia 34(6): 1007-1016. 
Santamaria, A., B. Vazquez-Roman, et al. (2005). "Selenium reduces the proapoptotic signaling associated to NF-kappaB pathway and stimulates glutathione peroxidase activity during excitotoxic damage produced by quinolinate in rat corpus striatum." Synapse 58(4): 258-66.

Savaskan, N. E., A. U. Brauer, et al. (2003). "Selenium deficiency increases susceptibility to glutamate-induced excitotoxicity." Faseb Journal 17(1): 112-4.

Scarmeas, N., L. S. Honig, et al. (2009). "Seizures in Alzheimer disease: who, when, and how common?" Arch Neurol 66(8): 992-7.

Schomburg, L., U. Schweizer, et al. (2003). "Gene disruption discloses role of selenoprotein P in selenium delivery to target tissues." Biochem J 370(Pt 2): 397-402.

Schwarz, K., L. A. Porter, et al. (1972). "Some regularities in the structure-function relationship of organoselenium compounds effective against dietary liver necrosis." Ann N Y Acad Sci 19(2): 200-14.

Schwarz, K., J. A. Stesney, et al. (1959). "Relation between selenium traces in L-cystine and protection against dietary liver necrosis." Metabolism 8(1): 88-90.

Schweizer, U., A. U. Brauer, et al. (2004). "Selenium and brain function: a poorly recognized liaison." Brain Res Brain Res Rev 45(3): 164-78.

Sharma, V., B. Nehru, et al. (2010). "Antioxidant potential of curcumin against oxidative insult induced by pentylenetetrazol in epileptic rats." Methods Find Exp Clin Pharmacol 32(4): 227-32.

Sisodiya, S. M. and H. C. Mefford (2011). "Genetic contribution to common epilepsies." Curr Opin Neurol 24(2): 140-5.

Small-Howard, A. L. and M. J. Berry (2005). "Unique features of selenocysteine incorporation function within the context of general eukaryotic translational processes." Biochem Soc Trans 33(Pt 6): 1493-7.

Sozmen, V., S. Baybas, et al. (2011). "Frequency of epilepsies in family members of patients with different epileptic syndromes." Eur Neurol 65(1): 4-9.

Squires, J. E. and M. J. Berry (2008). "Eukaryotic selenoprotein synthesis: mechanistic insight incorporating new factors and new functions for old factors." IUBMB Life 60(4): 232-5.

Stadtman, T. C., J. N. Davis, et al. (1989). "Biochemical and genetic analysis of Salmonella typhimurium and Escherichia coli mutants defective in specific incorporation of selenium into formate dehydrogenase and tRNAs." Biofactors 2(1): 35-44.

Stefani, A., F. Spadoni, et al. (1997). "Voltage-activated calcium channels: targets of antiepileptic drug therapy?" Epilepsia 38(9): 959-65.

Steinert, P., D. Bachner, et al. (1998). "Analysis of the mouse selenoprotein P gene." Biological Chemistry 379(6): 683-691.

Steinert, T., H. Baier, et al. (2011). "Epileptic Seizures During Treatment with Antidepressants and Neuroleptics." Fortschr Neurol Psychiatr 79(3): 138-143.

Strzelczyk, A., M. Cenusa, et al. (2011). "Management and long-term outcome in patients presenting with ictal asystole or bradycardia." Epilepsia 52(6):1160-7.

Sun, Y., J. A. Butler, et al. (2001). "Glutathione peroxidase activity and selenoprotein W levels in different brain regions of selenium-depleted rats." Journal of Nutritional Biochemistry 12(2): 88-94.

Suzuki, Y. (2011). "Molecular basis of neurogenetic diseases." Brain Dev. doi:10.1016/ j.physletb.2003.10.071 
Takebe, G., J. Yarimizu, et al. (2002). "A comparative study on the hydroperoxide and thiol specificity of the glutathione peroxidase family and selenoprotein P." Journal of Biological Chemistry 277(43): 41254-8.

Tamura, T. and T. C. Stadtman (2002). "Mammalian thioredoxin reductases." Methods Enzymol 347: 297-306.

Tome Ada, R., P. M. Ferreira, et al. (2010). "Inhibitory action of antioxidants (ascorbic acid or alpha-tocopherol) on seizures and brain damage induced by pilocarpine in rats." Arq Neuropsiquiatr 68(3): 355-61.

Tsai, J. J. (2005). "Mortality of epilepsy from national vital statistics and University epilepsy clinic in Taiwan." Epilepsia 46 Suppl 1(1): 8-10.

Tujebajeva, R. M., P. R. Copeland, et al. (2000). "Decoding apparatus for eukaryotic selenocysteine insertion." EMBO Rep 1(2): 158-63.

Urbach, H. (2005). "Imaging of the epilepsies." Eur Radiol 15(3): 494-500.

Vendeland, S. C., M. A. Beilstein, et al. (1993). "Purification and properties of selenoprotein W from rat muscle." Journal of Biological Chemistry 268(23): 17103-7.

Verrotti, A., G. Loiacono, et al. (2011). "Pharmacotherapy for children and adolescents with epilepsy." Expert Opin Pharmacother 12(2): 175-94.

Vezzani, A., J. French, et al. (2011). "The role of inflammation in epilepsy." Nat Rev Neurol $7(1): 31-40$.

Wang, G. S., D. Q. Geng, et al. (2010). "Protective effect of $\mathrm{Na}_{2} \mathrm{SeO}_{3}$ against cerebral ischemia-reperfusion injury to the hippocampal neurons in rats." Nan Fang Yi Ke Da Xue Xue Bao 30(10): 2336-9.

Weber, G. F., P. Maertens, et al. (1991). "Glutathione peroxidase deficiency and childhood seizures." Lancet 337(8755): 1443-4.

Westmark, C. J., P. R. Westmark, et al. (2010). "Alzheimer's disease and Down syndrome rodent models exhibit audiogenic seizures." J Alzheimers Dis 20(4): 1009-13.

Whanger, P. D. (2009). "Selenoprotein expression and function-selenoprotein W." Biochim Biophys Acta 1790(11): 1448-52.

Wilke, C., G. Worrell, et al. (2011). "Graph analysis of epileptogenic networks in human partial epilepsy." Epilepsia 52(1): 84-93.

Willmore, L. J. and J. J. Rubin (1981). "Antiperoxidant pretreatment and iron-induced epileptiform discharges in the rat: EEG and histopathologic studies." Neurology 31(1): 63-9.

Wirth, E. K., M. Conrad, et al. (2010). "Neuronal selenoprotein expression is required for interneuron development and prevents seizures and neurodegeneration." FASEB J 24(3): 844-52.

Wu, M., M. M. Kang, et al. (2010). "Selenium compounds activate early barriers of tumorigenesis." Journal of Biological Chemistry 285(16): 12055-62.

Xiong, S., W. R. Markesbery, et al. (2007). "Seleno-L-methionine protects against betaamyloid and iron/hydrogen peroxide-mediated neuron death." Antioxid Redox Signal 9(4): 457-67.

Xu, X. M., B. A. Carlson, et al. (2007). "New developments in selenium biochemistry: selenocysteine biosynthesis in eukaryotes and archaea." Biol Trace Elem Res 119(3): 234-41. 
Yang, G. Q. and Y. M. Xia (1995). "Studies on human dietary requirements and safe range of dietary intakes of selenium in China and their application in the prevention of related endemic diseases." Biomed Environ Sci 8(3): 187-201.

Yang, X. E., W. R. Chen, et al. (2007). "Improving human micronutrient nutrition through biofortification in the soil-plant system: China as a case study." Environ Geochem Health 29(5): 413-28.

Yasuda, S., H. Sugiura, et al. (2011). "p38 Map Kinase Inhibitors as Potential Therapeutic Drugs for Neural Diseases." Cent Nerv Syst Agents Med Chem 11(1): 45-59.

Yuzbasioglu, A., H. Karatas, et al. (2009). "Changes in the expression of selenoproteins in mesial temporal lobe epilepsy patients." Cell Mol Neurobiol 29(8): 1223-31.

Zafar, K. S., A. Siddiqui, et al. (2003). "Dose-dependent protective effect of selenium in rat model of Parkinson's disease: neurobehavioral and neurochemical evidences." Journal of Neurochemistry 84(3): 438-446.

Zhang, S., C. Rocourt, et al. (2010). "Selenoproteins and the aging brain." Mech Ageing Dev 131(4): 253-60.

Zhang, Y., Y. Zhou, et al. (2008). "Comparative analysis of selenocysteine machinery and selenoproteome gene expression in mouse brain identifies neurons as key functional sites of selenium in mammals." Journal of Biological Chemistry 283(4): 2427-2438. 


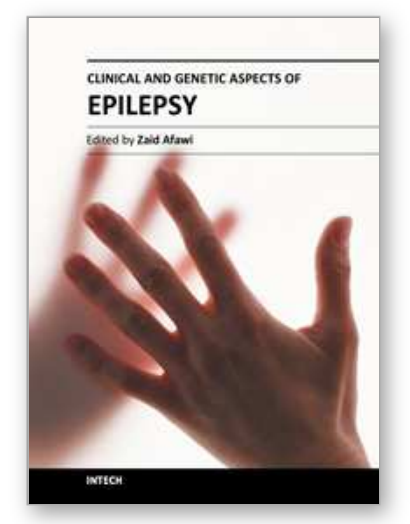

\author{
Clinical and Genetic Aspects of Epilepsy \\ Edited by Dr. Zaid Afawi
}

ISBN 978-953-307-700-0

Hard cover, 204 pages

Publisher Intech

Published online 15, September, 2011

Published in print edition September, 2011

This book on Epilepsy was conceived and produced as a source of information on wide range of issues in epilepsy. We hope that it will help health care providers in daily practices and increase their understanding on diagnosis and treatment of epilepsies. The book was designed as an update for neuroscientists who are interested in epilepsy, primary care physicians and students in health care professions.

\title{
How to reference
}

In order to correctly reference this scholarly work, feel free to copy and paste the following:

Caroline Rocourt, Ying Yu and Wen-Hsing Cheng (2011). Epilepsy: Selenium and Aging, Clinical and Genetic Aspects of Epilepsy, Dr. Zaid Afawi (Ed.), ISBN: 978-953-307-700-0, InTech, Available from:

http://www.intechopen.com/books/clinical-and-genetic-aspects-of-epilepsy/epilepsy-selenium-and-aging

\section{INTECH}

open science | open minds

\section{InTech Europe}

University Campus STeP Ri

Slavka Krautzeka 83/A

51000 Rijeka, Croatia

Phone: +385 (51) 770447

Fax: +385 (51) 686166

www.intechopen.com

\section{InTech China}

Unit 405, Office Block, Hotel Equatorial Shanghai

No.65, Yan An Road (West), Shanghai, 200040, China

中国上海市延安西路65号上海国际贵都大饭店办公楼405单元

Phone: +86-21-62489820

Fax: $+86-21-62489821$ 
(C) 2011 The Author(s). Licensee IntechOpen. This chapter is distributed under the terms of the Creative Commons Attribution-NonCommercialShareAlike-3.0 License, which permits use, distribution and reproduction for non-commercial purposes, provided the original is properly cited and derivative works building on this content are distributed under the same license. 